\title{
Movimento Body Positive no Instagram: reflexões sobre a estetização da saúde na sociedade neoliberal
}

\author{
Body Positive movement on Instagram: reflections about the \\ aestheticization of health in neoliberal society
}

\section{Movimiento Body Positive en Instagram: reflexiones sobre la estetización de la salud en la sociedad neoliberal}

\author{
Thais Nascimento Conde ${ }^{1, a}$ \\ thaisnconde@gmail.com | http://orcid.org/o000-0001-9926-1662 \\ Cristiane Marques Seixas ${ }^{2, b}$ \\ cris.marques.seixas@gmail.com | https://orcid.org/0000-0003-2630-9746
}

${ }^{1}$ Universidade do Estado do Rio de Janeiro, Programa de Pós-graduação em Alimentação, Nutrição e Saúde. Rio de Janeiro, RJ, Brasil.

2 Universidade do Estado do Rio de Janeiro, Instituto de Nutrição, Programa de Pós-graduação em Alimentação, Nutrição e Saúde. Rio de Janeiro, RJ, Brasil.

\footnotetext{
a Mestrado em Alimentação, Nutrição e Saúde pela Universidade do Estado do Rio de Janeiro.
}

${ }^{\mathrm{b}}$ Doutorado em Teoria Psicanalítica pela Universidade Federal do Rio de Janeiro.

\section{RESUMO}

Com o avanço das tecnologias de informação, as redes sociais estão inseridas diretamente no cotidiano dos indivíduos e refletem o modo como grupos e indivíduos constroem suas relações sociais, afetivas e laborais. Considerando que a percepção sobre os corpos é influenciada pelos canais de comunicação, este trabalho procura discutir o crescimento do movimento Body Positive ( $\mathrm{BoPo}$ ) em perfis do Instagram, tendo em vista a estetização da saúde e o efeito de influência e controle que são exercidos sobre a relação dos indivíduos com seus corpos. Para tanto, toma-se como referência a análise dos mecanismos neoliberais de controle e modulação de subjetividades marcados pela exigência de desempenho máximo e pela permanente concorrência consigo mesmo e com os outros. Procura-se apresentar uma reflexão crítica sobre a capacidade de captura dos mecanismos de controle em redes sociais que, em associação ao mercado capitalista, produzem novas roupagens para antigos dispositivos de poder.

Palavras-chave: Body Positive; Estetização da saúde; Redes sociais; Instagram; Neoliberalismo. 


\section{ABSTRACT}

With the advancement of information technologies, social media are inserted straight in people's daily life and reflect the way groups and individuals build their social, affective, and work relations. Considering that body perception is influenced by media channels, this paper aims to discuss the Body Positive movement increase on Instagram profiles, given the aestheticization of health and the influence and control effect over the relation of individuals with their bodies. Therefore, it takes as reference the analysis of neoliberal's control and subjectivity modulation mechanisms marked by both the exigency of maximum performance and the permanent competition with itself and the others. It seeks to present a critical reflection on the capture capacity of the social media control mechanisms that, associated with a capitalist market, produces new clothes to old power dispositives.

Keywords: Body positive; Aestheticization of health; Social media; Instagram; Neoliberalism.

\section{RESUMEN}

Con el avance de las tecnologías de la información, las redes sociales se insertan directamente en la vida diaria de las personas y reflejan la forma en que los grupos y las personas construyen sus relaciones sociales, afectivas y laborales. Teniendo en cuenta que la percepción de los cuerpos está influenciada por los canales de comunicación, este documento busca discutir el crecimiento del movimiento Body Positive (BoPo) en los perfiles de Instagram, en vista de la estetización de la salud, la influencia y el efecto de control que se ejercen sobre la relación de individuos con sus cuerpos. Con este fin, se toma como referencia el análisis de los mecanismos neoliberales para controlar y modular las subjetividades marcadas por la demanda de máximo rendimiento y competencia permanente consigo mismo y con los demás. Busca presentar una reflexión crítica sobre la capacidad de capturar mecanismos de control en las redes sociales que, en asociación con el mercado capitalista, producen ropa nueva para viejos dispositivos de energía.

Palabras claves: Body positive; Estetización de la salud; Reds sociales; Instagram; Neoliberalismo.

Contribuição dos autores:

Concepção e desenho do estudo: Thais Nascimento Conde e Cristiane Marques Seixas.

Aquisição, análise ou interpretação dos dados: Thais Nascimento Conde e Cristiane Marques Seixas.

Redação do manuscrito: Thais Nascimento Conde e Cristiane Marques Seixas.

Revisão crítica do conteúdo intelectual: Cristiane Marques Seixas.

Declaração de conflito de interesses: não há.

Fontes de financiamento: Conselho Nacional de Pesquisa e Desenvolvimento (CNPq).

Considerações éticas: não há.

Agradecimentos/Contribuições adicionais: não há.

Histórico do artigo: submetido: 29 mar. 2020 | aceito: 21 jul. 2020 | publicado: 22 mar. 2021.

Apresentação anterior: não houve.

Licença CC BY-NC atribuição não comercial. Com essa licença é permitido acessar, baixar (download), copiar, imprimir, compartilhar, reutilizar e distribuir os artigos, desde que para uso não comercial e com a citação da fonte, conferindo os devidos créditos de autoria e menção à Reciis. Nesses casos, nenhuma permissão é necessária por parte dos autores ou dos editores. 


\section{INTRODUÇÃO}

As redes sociais mostram cada vez mais sua influência em todas as esferas da vida social ao mesmo tempo que as espelha. Sua presença nos smartphones, por meio de aplicativos próprios, as torna acessíveis em tempo integral e reflete o modo como grupos e indivíduos constroem suas práticas coletivas e suas relações sociais, afetivas e laborais. Essa presença massiva nos impõe a reflexão sobre os efeitos coletivos que a tecnologia vem imprimindo em nossa sociedade, nos corpos e nas subjetividades contemporâneas.

No contexto social, foi a partir da década de 90 que assistimos ao surgimento da internet que passou gradativamente a consolidar-se como um dos principais meios de comunicação da atualidade, facilitando o acesso a conteúdos diversificados, ampliando as possibilidades de comunicação entre pessoas e a transmissão de informações. A ampla gama de opções de redes sociais existentes, juntamente com a facilidade de operálas, motivou a entrada de pessoas comuns no campo da comunicação. Nesse contexto, a ascensão da dita profissão 'blogueiro(a)' foi resultado da popularização dos blogs, que, desdobram-se posteriormente em outras ferramentas e em redes sociais tais como Facebook, Twitter, YouTube e Instagram. Atualmente os blogueiros são chamados de 'influenciadores digitais', caracterizando uma profissão à qual cada vez mais pessoas se dedicam.

Essas redes sociais refletem o modo como grupos e indivíduos constroem suas identidades, subjetividades e como se relacionam com seus corpos. Entre essas mídias sociais emergentes, destacamos para esse estudo o Instagram por se tratar de uma rede social cujo objetivo é o compartilhamento de imagens como o principal meio de transmitir a mensagem à audiência. Considerando que tanto a percepção sobre um corpo quanto a relação que cada um tem com o próprio corpo é influenciada pelos canais de comunicação, este trabalho procura discutir o crescimento do movimento Body Positive (BoPo) em perfis do Instagram, tendo em vista a estetização da saúde e o efeito de influência e controle que são exercidos sobre a relação dos indivíduos com seus corpos.

Para tanto foi realizada uma revisão integrativa de literatura a fim de identificar autores que investigam os impactos das redes sociais sobre a saúde, o corpo e as relações sociais, à luz de uma leitura foucaultiana do poder. Da mesma maneira, essas referências dialogam com autores que contribuíram mais recentemente com novas leituras dos conceitos desenvolvidos por Foucault, relacionando-os à sociedade neoliberal $\mathrm{e}$ digital. Por se tratar de um ensaio teórico, optou-se por analisar algumas postagens de perfis selecionados tendo em vista a presença e repercussão nas redes sociais de influenciadoras digitais que representam o movimento Body Positive. Sua popularidade foi identificada a partir de matérias jornalísticas sobre o movimento BoPo nas redes sociais e pela métrica de seguidores em cada perfil.

\section{NAVEGANDO NO BOPO}

Mais de 3 bilhões de pessoas usam as mídias sociais em todo o mundo, e a maioria destes usuários acessa suas plataformas escolhidas por meio de aparelhos móveis (KEMP, 2018). Cada vez mais tem se estabelecido na literatura que a sociedade está gradativamente inserida no meio social virtual. Compreendese essa transição devido ao contexto de evolução das tecnologias de informação. Em consequência disso, a internet se tornou uma fonte predominante de informações sobre normas sociais e aparências (BAIR; KELLY; SERDAR; MAZZEO, 2012).

No espaço criado pelas interações em rede e, lançando mão de conteúdos motivacionais e inspiradores, os influenciadores digitais são pessoas que se destacam por alguma temática específica e se tornam 'referência' para determinados assuntos, na medida em que arrastam uma legião de seguidores para seus perfis. Além da atuação intensiva e ostensiva dos influenciadores digitais, a viralização espontânea de acontecimentos na internet tem sido um fenômeno que atrai o interesse de especialistas e leigos. Trata-se de um efeito de 
marketing digital que faz com que determinados conteúdos se propaguem nas redes gerando um aumento estratosférico nos níveis de interação e engajamento (ALMEIDA; COSTA; COELHO; SCALCO, 2016).

Um dos casos viralizados na internet ocorreu quando a fotógrafa australiana Taryn Brumfitt postou no Facebook uma foto com o 'antes e depois' do próprio corpo (FELL, 2017). Esse tipo de montagem com fotos é usualmente compartilhado nas redes sociais quando os usuários fazem um comparativo da imagem do seu corpo em dois momentos distintos, geralmente o antes corresponde a um tipo físico não desejável e o depois a um tipo físico desejável socialmente. É comum observar essa prática por pessoas que buscam perder peso ou tonificar o corpo, basicamente por meio de dietas e exercícios físicos, utilizando este registro fotográfico como um fator motivacional. Taryn fez o caminho inverso postando no Facebook uma foto 'antes e depois' que causou grande surpresa aos seus seguidores e viralizou.

Taryn é uma mãe de família que, após ter o segundo filho, se deparou com alguns quilos a mais associado a uma baixa autoestima e um grande desconforto com a imagem do seu corpo. Para lidar com isso, adotou um estilo de vida baseado em dietas e treinos físicos rigorosos, alcançando o corpo 'perfeito', moralmente aceito e desejado. Ao participar de um concurso de fisiculturismo, Taryn se deu conta de que de todas as mulheres que estavam com ela no palco expondo seus corpos magros e com músculos definidos estavam insatisfeitas. Essas reflexões levaram Taryn a entender a necessidade de 'abraçar seu corpo' do jeito que ele era, não reproduzindo os estereótipos culturais que nos constrangem a desejar e agir sempre da mesma maneira.

Em decorrência dessas reflexões, a postagem viralizada (Figura 1) apresentava uma foto do 'antes' que exibia seu corpo magro, tonificado e bronzeado em uma competição de fisiculturismo, enquanto a foto do 'depois' retratava seu corpo nu, escondendo cuidadosamente as partes íntimas, mas exibindo seu volume e suas curvas, descrevendo por meio de imagens seu processo de aceitação corporal após a maternidade.

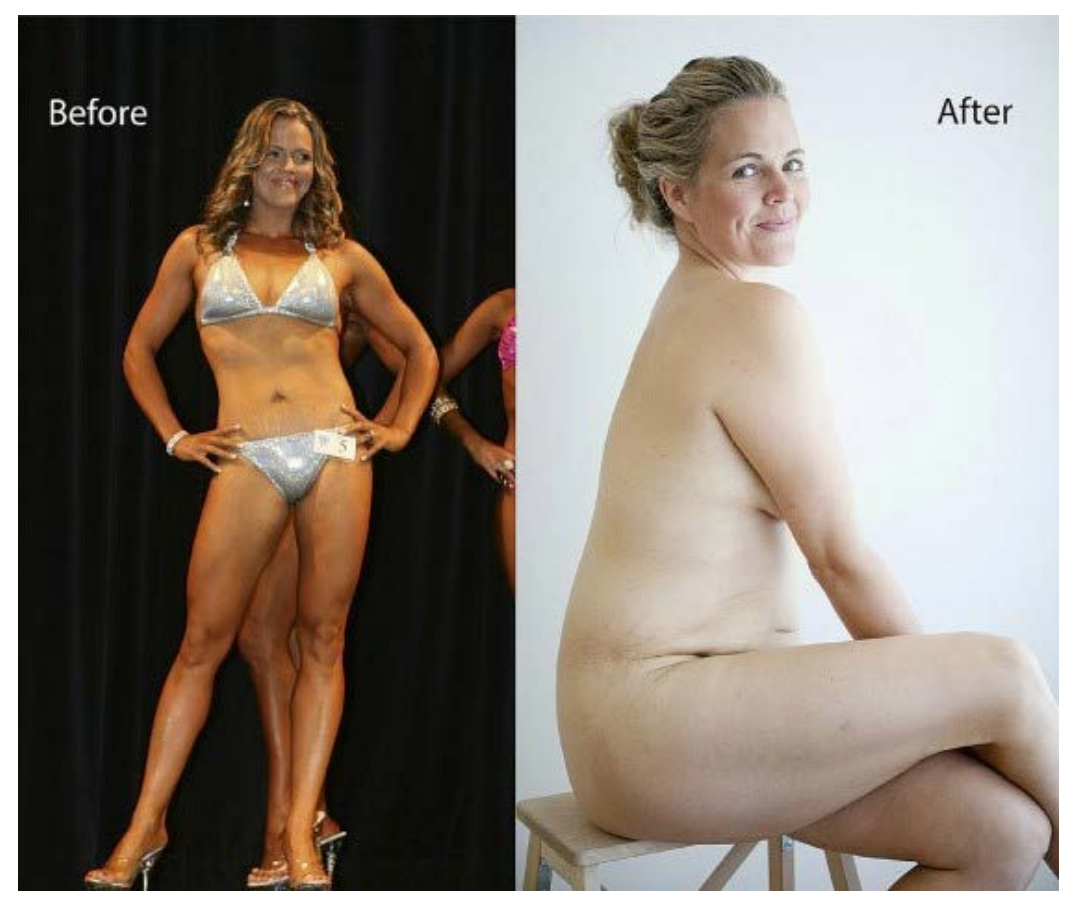

Figura 1 - Antes e depois de Taryn Brumfitt Fonte: Fell (2017).

A publicação, que ganhou destaque internacional, teve muitos comentários negativos, mas também fez com que Taryn recebesse muitos depoimentos e pedidos de ajuda de mulheres que se sentiam como ela e que tinham dificuldades de aceitar seus próprios corpos. Com essa repercussão, Taryn protagonizou a 
difusão nas redes sociais do movimento que valoriza uma imagem corporal positiva, fundando o Body Image Movement, cuja missão é "acabar com a epidemia global de ódio ao corpo por meio de recursos educacionais, palestras e conteúdo inspirador e motivacional” (BODY IMAGE MOVEMENT, c2019, tradução nossa). A partir de um financiamento coletivo, Taryn arrecadou recursos que foram utilizados na produção do documentário Embrace (2016), no qual ela viaja pelo mundo para conhecer histórias pessoais de superação dos conflitos com o corpo e padrões de beleza estabelecidos em diversas culturas.

Seguindo a tendência de ampliação de temáticas que capturavam cada vez mais pessoas, as redes sociais contribuíram para a amplificação do debate sobre o estigma corporal. Se Taryn, juntamente com outras mulheres, foi a protagonista nas redes sociais dessa busca por interrogar os efeitos prejudiciais dos padrões de corpo magro, pode-se afirmar que no mundo off-line a preocupação com essa temática não é recente.

O movimento Body Positive é discutido há muito tempo, mesmo sem estar categorizado por essa terminologia, pois tem a finalidade de expor a discussão sobre a não marginalização dos corpos fora dos padrões estéticos dominantes (ARANDAS, 2018). A origem do movimento não tem autoria específica e temporal, mas acredita-se que tenha ganhado popularidade a partir do movimento feminista na década de 1960, com início na segunda e terceira ondas feministas, nas quais as questões da política corporal e discriminação contra corpos gordos passaram a ser discutidos entre as mulheres (CWYNAR-HORTA, 2016). Em 1996, Connie Sobczak e Elizabeth Scott fundaram The Body Positive Institute, nos Estados Unidos, com o propósito de criar uma comunidade livre de julgamentos sociais que ajudasse as pessoas a criar "relacionamentos felizes e pacíficos com seus corpos" (THE BODY POSITIVE INSTITUTE, c2019, tradução nossa).

Os perfis selecionados como lócus de observação do crescimento do movimento BoPo nas redes sociais foram de Tess Holliday e Jayne Crabbe, que são ativistas internacionais desse movimento. Tess Holliday atraiu muitos olhares sendo a primeira mulher gorda a estar em uma capa de uma revista feminina internacional, renomada por apresentar mulheres magras e famosas. O lançamento da autobiografia de Jayne Crabbe chamou atenção para a gravidade dos transtornos alimentares, tanto para leigos quanto profissionais da saúde. Essas protagonistas têm mais de 1 milhão de seguidores no Instagram, o que revela sua popularidade na rede social e o poder de influência sobre outras pessoas. Como mencionado anteriormente, o documentário de Taryn Brumfitt ganhou relevância mundial e foi disponibilizado no Brasil em plataformas de streaming. Por seu protagonismo em colocar em pauta a questão da imagem do corpo fora dos padrões e pelo potencial de divulgação e internacionalização da discussão, o perfil de Tarym Brumfitt também foi observado. As imagens trazidas no presente ensaio representam um recorte intencional da amostra de 10 imagens recolhidas em cada perfil nos meses de agosto, outubro e dezembro de 2019.

A partir da seleção destes perfis, nota-se que o percurso dessas ativistas do BoPo não é muito diferente, mas vale a pena conhecê-lo. Tess Holliday é uma modelo 'plus size' feminista que em 2012 criou a conta de Instagram @effyourbeautystandards dando início à campanha de mesmo nome. Sua empreitada visava a responder às mensagens com que frequentemente nos deparamos na mídia que dizem que mulheres não são bonitas se estiverem acima do tamanho 10 (que no Brasil e Europa corresponderia ao tamanho 40). Sua campanha convocava as mulheres a serem mais amorosas com seus corpos e mostrarem ao mundo que elas podem ser 'sexy' e também estar na moda mesmo com corpos fora dos padrões da indústria da moda. Atualmente ela é a maior influenciadora digital do Body Positive com mais de 2.1 milhões de seguidores. Sua conta pessoal no Instagram aponta para uma forte ligação com a indústria da moda voltada para o nicho das mulheres gordas.

Megan Jayne Crabbe é também uma das mais eminentes influenciadoras digitais com 1.3 milhões de seguidores no Instagram. Em seu perfil @bodyposipanda Jayne compartilha suas experiências sobre a 
vida com anorexia e sua fase de recuperação da doença. Utilizando fotos e frases motivacionais relativas ao Body Positive, Crabbe procura ajudar outras mulheres que vivem na mesma situação a conseguirem uma mudança de atitude mental em relação a si mesmas. Figura como autora do bestseller Body Positive Power: how to stop dieting, make peace with your body and live lançado em 2017, no qual defende uma nova maneira de as pessoas se verem e a possibilidade de construir um mundo onde todos os corpos são festejados, onde não existe uma ‘dieta do corpo de biquíni’ e 97\% das mulheres não odeiam sua aparência.

Ao destacarmos algumas postagens dos perfis selecionados, pode-se identificar elementos que contribuem significativamente para torná-las importantes influenciadoras digitais do movimento BoPo. Primeiramente destaca-se a permanente exibição do corpo associado à conquista de uma nova relação livre dos ditames sociais ou mesmo a ressignificação deles (Figura 2).
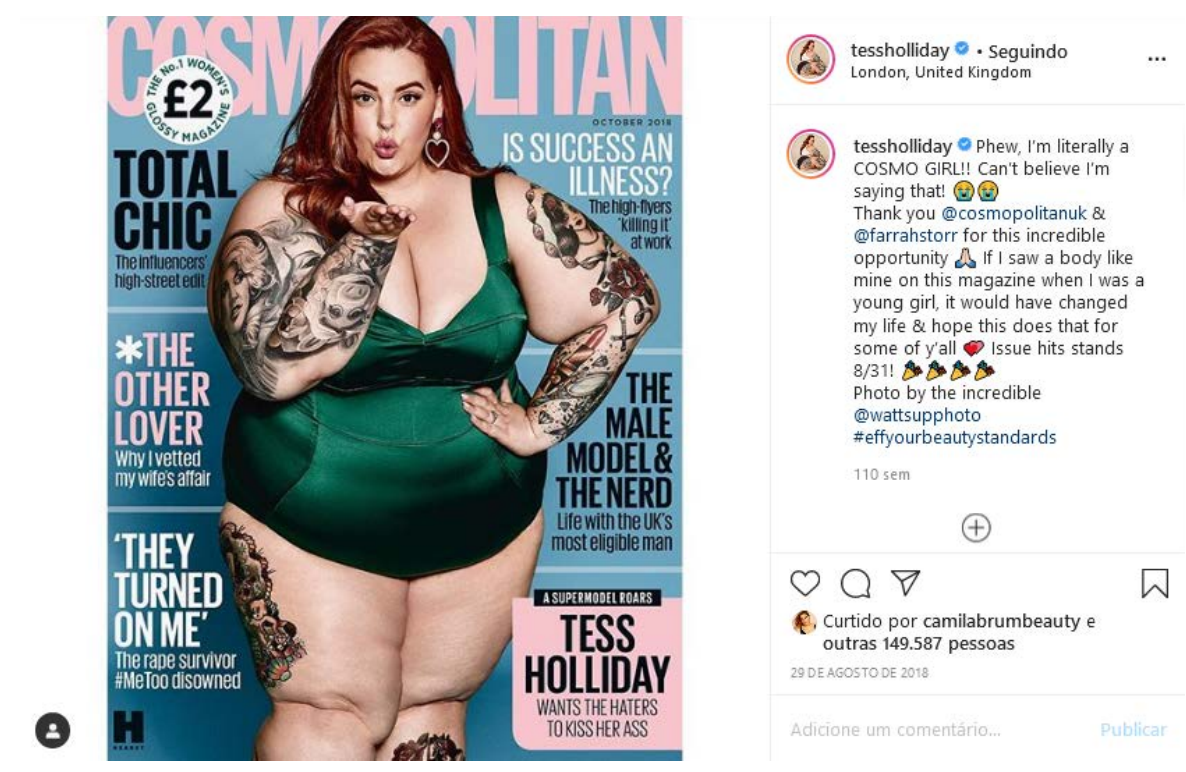

Figura 2 - Publicação do perfil @tessholiday, de 29 de agosto de 2018 Fonte: Instagram @tessholiday (2018).

Postagens com roupas que tradicionalmente só deveriam ser usadas por pessoas magras (biquínis, lingeries, roupas justas ou de cores vibrantes e chamativas) ou em lugares pouco convencionais (piscina, praia, festas, momentos românticos), fazem dessas imagens elementos importantes de sugestionabilidade para os seguidores (Figuras 2 e 3 ).
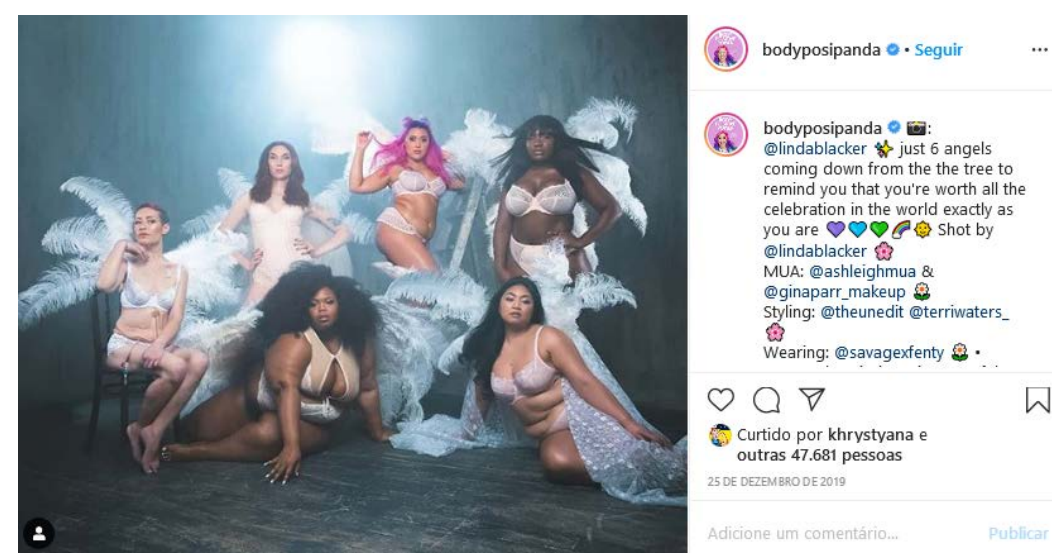

Figura 3 - Publicação do perfil @bodyposipanda, de 25 de dezembro de 2019 Fonte: Instagram @bodyposipanda (2019). 
A mensagem que se passa, muitas vezes expressa nas legendas, é que todos podem alcançar a reconquista do corpo, e as fórmulas de como fazê-lo proliferam ao sabor dos discursos de autoajuda que muito se aproximam daqueles discursos neoliberais do empreendedorismo de si (Figuras 3 e 4). A reconciliação com o próprio corpo, com as marcas, cores e dobras que ele comporta, depende de uma viagem em direção a si mesmo, como o resgate do elo perdido ou de uma subjetividade outrora amordaçada e excluída.

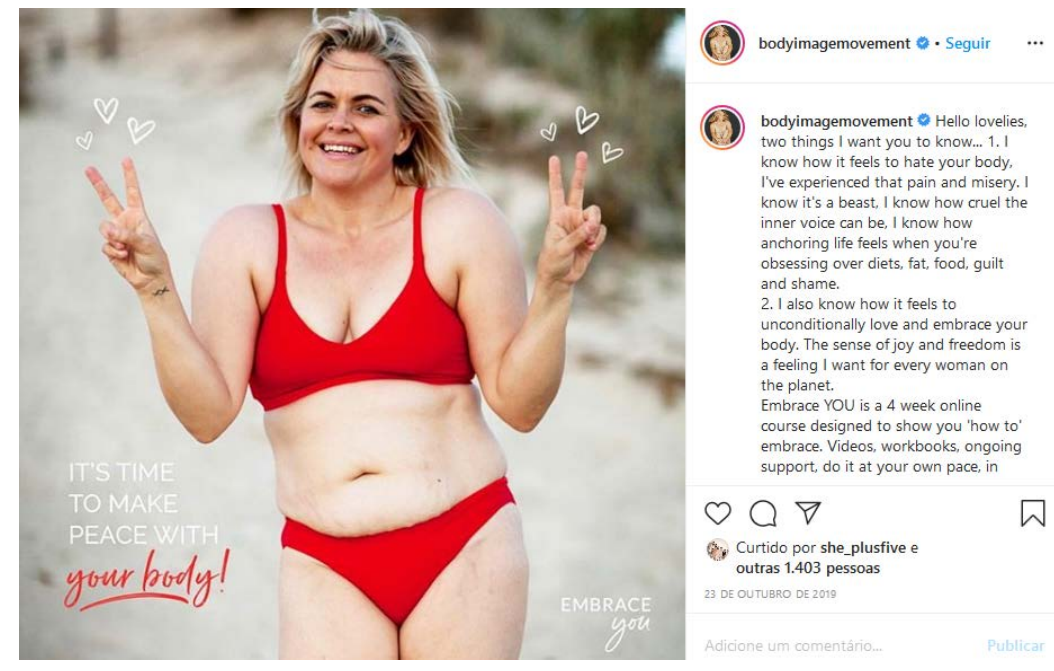

Figura 4 - Publicação do perfil @bodyimagemovement, de 21 de outubro de 2019 Fonte: Instagram @bodyimagemovement (2019).

Outro aspecto relevante é a oferta de produtos e serviços associados ao movimento BoPo. Alguns perfis são verdadeiras vitrines da causa e justificam-se pela ampliação do efeito subjetivo que prometem entregar por meio dessas ofertas. São cursos, serviços de maquiagem, roupas e objetos símbolo da causa que defendem que têm como efeito final a ampliação de um mercado consumidor e, inevitavelmente, um relativo enriquecimento dessas influenciadoras (Figuras 5, 6 e 7).

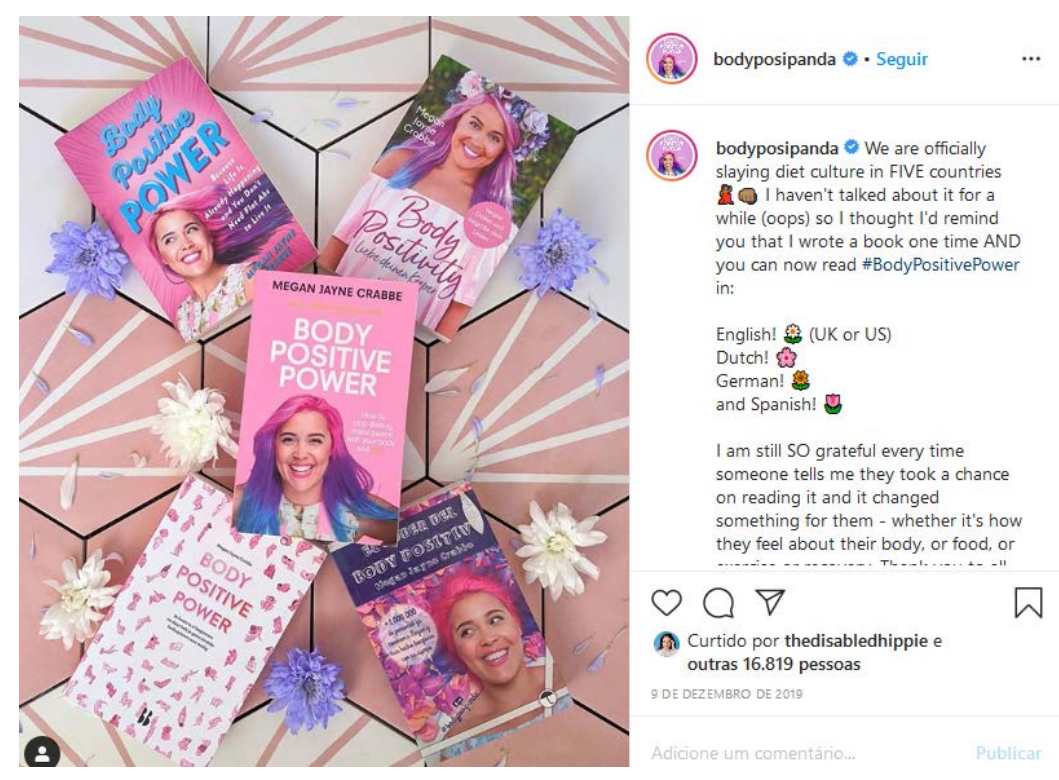

Figura 5 - Publicação do perfil @bodyposipanda, de 9 de dezembro de 2019 Fonte: Instagram @bodyposipanda (2019). 


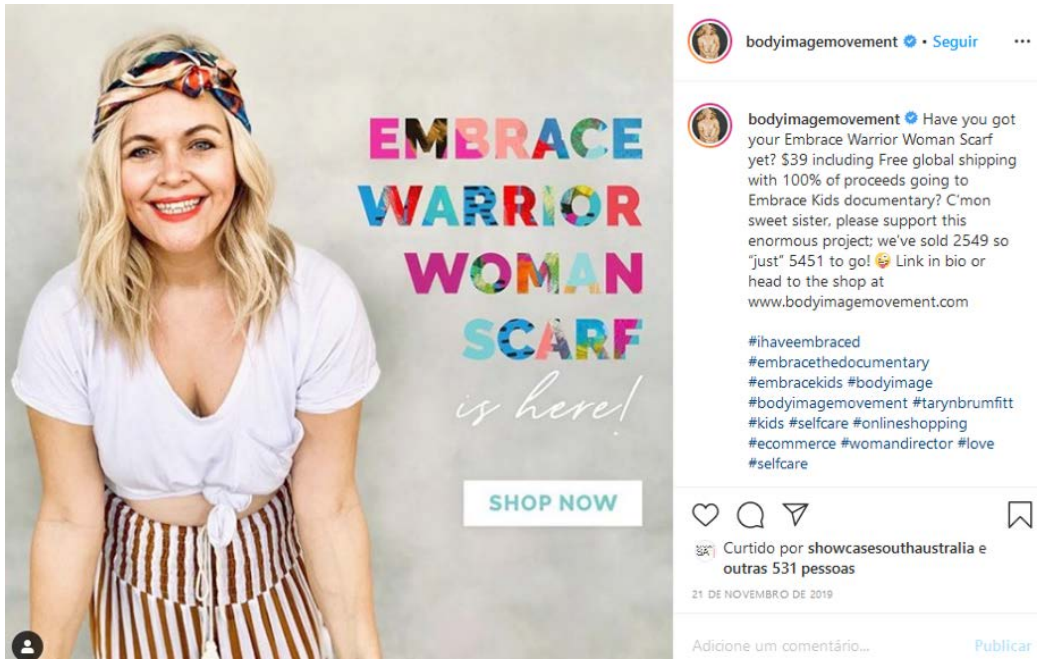

Figura 6 - Publicação do perfil @bodyimagemovement, de 22 de novembro de 2019 Fonte: Instagram @bodyimagemovement (2019).
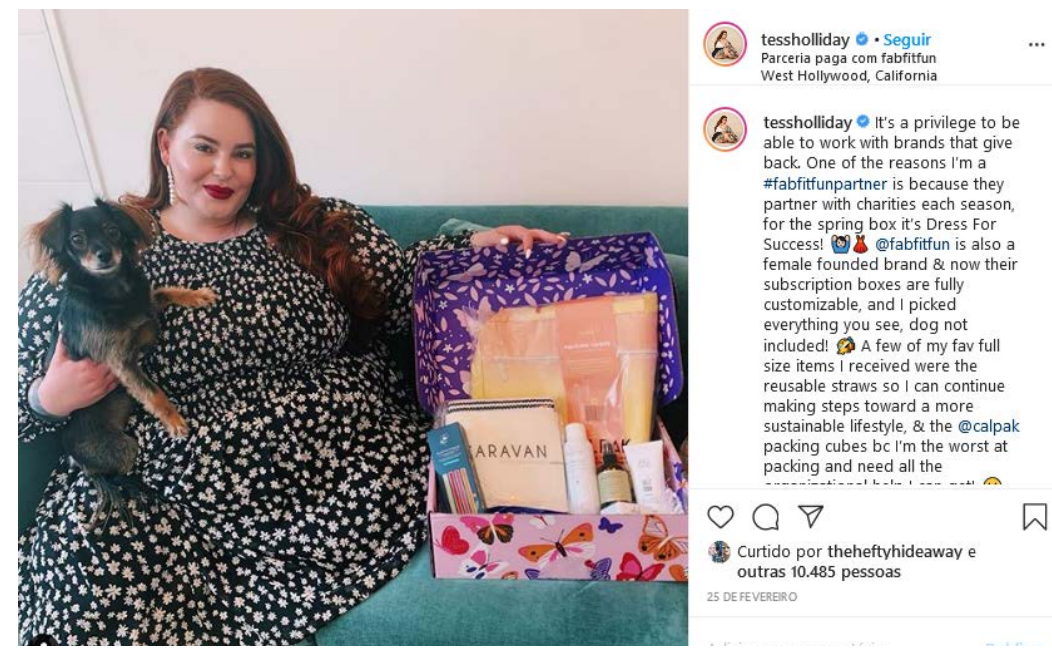

Figura 7 - Publicação do perfil @tessholiday, de 28 de fevereiro de 2020

Fonte: Instagram @tessholiday (2020).

Ao publicar imagens de seus corpos nos perfis do Instagram, essas mulheres passaram a representar coletivamente uma parcela de pessoas que se identificavam com as imagens e se sentiam oprimidas e discriminadas por não estarem dentro de um padrão de beleza corporal. Para a identificação do movimento entre os usuários da rede, em particular no Instagram, a hashtagi mais utilizada é a abreviação de Body Positive, \#BoPo, mas também são bastante frequentes outras hashtags tais como, \#selflove, \#bodypositive, \#goldenconfidence, \#plussize, \#effyourbeautystandards entre outras. Os princípios do BoPo são inerentes à elaboração de uma nova cultura do corpo, que propõe a exposição dos corpos como eles são, promovendo a autoaceitação e a representatividade de todas as formas corporais no mundo.

Arandas (2018) observa que, quando os usuários adeptos do Body Positive expõem seus corpos nas redes sociais, estão colocando o corpo estigmatizado em um debate político, acompanhado secundariamente de todas as experiências e o contexto sócio-histórico que esse corpo passou. Segundo Goffman (1988), os atributos sociais e ambientais são favoráveis à ocorrência da estigmatização dos indivíduos, o que

i As hashtags são recursos utilizados para categorizar os conteúdos publicados nas redes sociais, ou seja, cria uma interação dinâmica do conteúdo com os outros integrantes da rede social, que estão ou são interessados no respectivo assunto publicado. É formada por uma palavra-chave precedida pelo símbolo \#. 
leva à naturalização de certos comportamentos e à desvalorização de outros. A estigmatização produz a categorização dos indivíduos a partir da aparência física e, em relação ao movimento Body Positive, a característica que ganha destaque é o peso corporal, em detrimento de estigmas mais tradicionais como raça e etnia. Dessa forma, o corpo que circula nas postagens dos perfis BoPo do Instagram, independentemente do seu formato físico, é tratado como um campo de disputa envolvendo diferentes saberes, práticas e imaginários sociais.

\section{SAÚDE E BELEZA: O IMAGINÁRIO NA REDE}

No cenário contemporâneo, o bem-estar corporal atrai a atenção da indústria da beleza e da saúde, aproximando-o cada vez mais da propaganda e dos meios de comunicação em massa. A revolução tecnológica, por sua vez, abriu espaço para a agilidade na produção de informações e para o estímulo ao consumo. A transição do movimento de folhear uma revista para a tela touch aproxima e integra o corpo do usuário ao conteúdo digital, proporcionando o pertencimento ao mundo conectado. Logo, as dietas das revistas ultrapassam o espaço físico limitado das bancas de jornais e avançam para a integralidade nos dispositivos digitais em livre acesso. Assim, a disseminação das práticas sociais na internet gera um efeito que leva o indivíduo a reproduzi-las em redes sociais, pois desta forma demostram o desempenho esperado por seu círculo desejado. Segundo Almeida, Costa, Coelho e Scalco (2016), há uma robusta literatura para explicar os fatores sociais e psicológicos que influenciam o comportamento de disseminação nas redes sociais. Além dos fatores motivacionais que se relacionam ao envolvimento do usuário, os autores destacam que os diferentes tipos de conteúdo também têm efeito sobre esse comportamento.

Por meio das ferramentas de acesso e busca no espaço cibernético, os usuários interagem e criam laços sociais, sendo possível incorporar ao que Ortega (2008) descreve como biossociabilidade. Constitui-se uma nova forma de sociabilidade em que indivíduos partilham uma identidade que se organiza segundo critérios de saúde, e se conectam com o propósito de compartilharem experiências sobre saúde e doença ou em prol do ativismo sobre desenvolvimentos biomédicos. Os diversos blogs de emagrecimento, dietas específicas, exercícios físicos ou aqueles que envolvem um comer transtornado como os pro-anorexia e bulimia, assim como os blogs e perfis BoPo são exemplos dessa biossociabilidade. O espaço virtual serve de ferramenta tecnológica para a interação entre os sujeitos, e normalmente os depoimentos pessoais são compartilhados (rotina, cardápios, quantidade de calorias e exercícios) em favor de um envolvimento ativista.

Essa atividade que atrela um determinado tipo de discurso à saúde e beleza é perceptível no Instagram e em outras redes sociais, seja por meio de legendas ou hashtags ou pela própria temática da foto publicada. As imagens provocam um jogo de linguagem e conteúdo não-verbal que, na qualidade de discursos imagéticos, são estruturantes do imaginário social (FOUCAULT, 2010).

Segundo Ferreira (2015), podemos entender essa valorização dos parâmetros estéticos como definidores de saúde como um processo de estetização da saúde, desenvolvendo nos indivíduos a necessidade de corresponder a um modelo idealizado de beleza que é estabelecido socialmente. Tal processo teve início nos anos 80 , quando ocorreu um crescimento considerável do mercado relacionado à manutenção do corpo belo, como o aumento de cirurgias estéticas e alimentos em cápsulas (WITT; SCHNEIDER, 2011). Podemos considerar a estetização da saúde como um corolário da medicalização da sociedade que, segundo Peter Conrad (2007), corresponderia à transformação de problemas não médicos em problemas médicos que passam a ser tratados como doença, distúrbio ou transtorno, contribuindo para determinar o que é estar doente e, consequentemente, o que é estar saudável. A estetização da saúde faz com que ela esteja associada a um determinado ideal estético corporal, ao mesmo tempo que agrega um estatuto de doença a tudo aquilo que não se enquadra no padrão estético aceito socialmente. 
A beleza como horizonte a ser conquistado e o ideal estético corporal dela derivado constituem uma armadilha que se insere em um ciclo do consumo e dieta. Em outras palavras, a não adequação do corpo leva os indivíduos a se sentirem impróprios e deslocados, despertando o desejo de 'consumir' dietas restritivas, atividade física exaustiva, jejuns prolongados, diuréticos, laxantes, ou qualquer outra prática que leva, minimamente, à conquista do corpo ideal e não da saúde. Nesse sentido, é preciso levar em consideração as relações que constituem a sociedade capitalista de consumo, em que essa associação entre a estética e uma cultura medicalizada vem contribuindo para a idealização de corpos 'perfeitos' e 'válidos' como aqueles que apresentam magreza, beleza e elegância. Esses ‘corpos válidos' são os que pertencem a um certo estereótipo em que são desconsideradas as diversidades de gênero, classe social, etnia e faixa etária, constituindo uma armadilha que leva à prática de dietas que, em contrapartida, aquecem o mercado do saudável.

No que diz respeito ao excesso de peso e aos padrões estéticos a ele associados, a medicalização da obesidade substitui causas morais tradicionalmente atreladas a essa condição corporal passando a rotulá-la como 'doença'. Dessa forma, justifica-se a luta contra o excesso de peso que escamoteia o caráter moralizante desse processo, na medida em que a busca pela saúde fornece um pretexto para que todos possam atacar o indivíduo obeso e encarar isso como uma tentativa de combate à obesidade (FRANCISCO; DIEZ-GARCIA, 2015).

Diante disto, o binômio saúde-beleza, no qual o segundo termo é o determinante(VILHENA; MEDEIROS; NOVAES, 2005), se fundamenta na intervenção médica e justifica modulações de comportamentos para a manutenção de um corpo magro, livre de patologias, atlético e belo. A saúde passa também a possuir um padrão estético vinculado a mensagens de sucesso, autocontrole e aceitação (WITT; SCHNEIDER, 2011), constituindo aparentemente um caminho legítimo e seguro para a felicidade individual. Nesse sentido, a sociedade contemporânea, refém da pressão cultural e social para obter corpo magro, é precursora de discursos gordofóbicos que reforçam a construção de uma 'verdade absoluta'. O discurso construído acerca da patologização da obesidade é disfarçado por um discurso sobre saúde e cuidados médicos a partir da hipótese de que um corpo não obeso é livre de doença, excluindo a problematização da moralidade sobre este corpo (SEIXAS; BIRMAN, 2012).

Contudo, tal discursividade, que foi ganhando corpo ao sustentar a busca pela magreza associada à saúde, teve efeitos colaterais. Essa ligação perigosa resultou na proliferação de orientações que visavam ao autocontrole permanente, o que promoveu, em certa medida, uma preocupação excessiva com a alimentação e peso corporal, levando, em última análise, à perda da autonomia individual e ao aprisionamento das práticas alimentares cotidianas em práticas precursoras de transtornos alimentares. No mundo virtual, o crescimento de blogs pró-Ana e pró-Mia é o testemunho do efeito de exacerbação das práticas que seriam saudáveis, alimentadas pela proliferação de orientações por pessoas específicas, as blogueiras, que passaram a influenciar o modo de viver de pessoas comuns (COUTINHO; PRADO; SEIXAS, 2019).

Na esteira dessas mutações no discurso sobre o corpo e a saúde, vimos o despontar de uma nova categoria de culto ao corpo. A cultura fitness surgiu nos anos 1980 como reflexo da medicalização, da estetização da saúde e da exigência permanente de autocontrole e alta performance. O conceito de fitness está amplamente associado a diversos seguimentos e naturalizado na vida cotidiana. As informações acerca do conteúdo fitness, divulgadas pelos meios de comunicação de massa e propagadas nos ambientes virtuais, fomentam o senso comum sobre os diferentes interesses pelo corpo (SEIXAS; LUCENA, 2016). Os protagonistas dos perfis vinculados à divulgação de dieta e exercícios são considerados 'blogueiros fitness' e, na qualidade de influenciadores digitais, transmitem um estilo de vida visualmente fácil, provocando frustração àqueles que vislumbram alcançar este ideal. 
No estudo de Tiggemann e Zaccardo (2016) foi realizada uma análise a partir da hashtag \#fitspiration ${ }^{\mathrm{ii}}$ no Instagram que apontou que a maioria das imagens era de mulheres de corpo magro e tonificado, realizando exercícios ou utilizando equipamentos de exercício, ou de alimentos saudáveis. Algumas imagens estavam associadas a frases de caráter motivacional como "Não crescemos quando as coisas são fáceis; mudamos quando enfrentamos desafios" (TIGGEMANN; ZACCARDO, 2016, p. 62) ou relacionadas à boa forma, como por exemplo "Exercícios para estar em forma, não magro" (p. 62). Os autores consideram que a \#fitspiration pode oferecer um efeito positivo de inspiração e promoção da saúde física e mental, porém, em alguns aspectos, a veiculação repetida de corpos magros e tonificados pode provocar entendimento único sobre imagem corporal e saúde, trazendo insatisfação corporal e baixa autoestima. Portanto, os indivíduos expostos a esse padrão estético acreditam que, alcançando esse modelo de corpo, conseguirão também alcançar todas as qualidades que lhe são associadas, ou, ao menos, deveriam demonstrar que estão buscando tal corpo, sob o risco de serem estigmatizados (ARANDAS, 2018).

Tendo em vista que o estigma (GOFFMAN, 1988) refere-se a uma marca social e moral indesejável que desqualifica os sujeitos devido à não-adequação aos padrões vigentes de aparência física, podemos afirmar que o estigma da gordura é uma construção social que desqualifica os sujeitos, atribuindo juízos de valor pejorativos ao excesso de peso e identificando o gordo como preguiçoso e descontrolado (MATTOS; LUZ, 2009).

Na discussão entre os tipos de corpos que são exibidos nas redes sociais, há uma normalização da saúde associada a corpo atlético ou magro e ainda uma discriminação aos que exibem os seus corpos gordos publicamente. O preconceito em relação à gordura corporal surge a partir desta naturalização e se desenvolve apoiada em uma moralidade acerca de um corpo gordo, reforçando a estigmatização do corpo não adequado às normas sociais relacionadas à saúde e beleza.

\section{INFLUÊNCIA, CONTROLE E DISPOSITIVOS DE PODER}

Nesse contexto social virtual, até que ponto o corpo e o desejo de obter um corpo magro se convertem em um objeto de poder? Atualmente não podemos nos furtar a refletir sobre a expansão dos efeitos de poder em tempos em que a indiferenciação entre real e virtual acompanha o dia a dia de quem habita nesse mundo conectado. Com as novas possibilidades midiáticas, temos ambientes de sociabilidade que reduziram as distâncias e alteraram a forma de perceber, pensar e contabilizar o real (SODRÉ, 2002). Assim, a dicotomia real/virtual nunca soou tão inapropriada (CASTRO, 2012), uma vez que o digital está disseminado pelo mundo a ponto de assistirmos à hibridização da sociedade contemporânea, que transita pelo ambiente off-line e on-line de modo corriqueiro, tornando o virtual uma expansão do real.

Se a comunicação cria a possibilidade de influenciar as normas e os padrões de beleza, isso não é diferente no meio virtual no qual a comunicação on-line reforça ideais sociais referentes ao corpo (FURTADO, 2009). Kozinets (1998) aponta que as relações exercidas em comunidades virtuais não se restringem às comunicações mediadas por computador, pois também há influência na vida dos usuários envolvidos para além dessa situação. Nas novas modalidades de formação de grupos em ambientes digitais, os indivíduos almejam algo em comum: seja um detalhe corporal, um desejo, um ideal político, uma crença religiosa ou um mesmo objeto. Segundo Peixoto (2014), redes sociais digitais se caracterizam em sua essência pela construção de agrupamentos de indivíduos que produzem e reproduzem identidades para fins de associação e afinidade no ambiente on-line.

ii Hashtag utilizada para marcar imagens destinadas a inspirar as pessoas a se tornarem saudáveis, definidas e saradas. 
Contudo, o modo de encontrar pares afins foi fortemente alterado, por exemplo, no Facebook ou no Instagram, pelo algoritmo EdgeRankiii, que, a partir de dados pessoais e histórico de navegação dos usuários, direciona as postagens que supostamente mais os agradarão. Os usuários terão minimamente afinidade com algum traço do usuário daquele perfil, reforçando o efeito de sugestionabilidade entre os membros de um grupo pela repetição das atitudes de outros membros ou pelo aval garantido pelo número de likes ou interações. A partir do momento em que seus relacionamentos on-line são ditados por afinidades, observase que "o único som que escutam é o eco de suas próprias vozes" (BAUMAN, 2016). Os grupos tornam-se uníssonos, e a diferença é tratada a partir da exclusão.

Essa característica de grupo em que crenças e valores individuais ficam à sombra do valor 'maior' que une aqueles indivíduos enquanto 'massa' gera uma espécie de apagamento das individualidades, cujo efeito mais perigoso é que o grupo fique vulnerável à manipulação. Segundo Lanier (2018), o problema, portanto, não está no fato de que a tecnologia nos permita ampliar os horizontes de conexão com pessoas próximas ou a grandes distâncias, nem no imediatismo que as redes sociais proporcionam e alimentam, ou até mesmo que passemos muitas horas olhando para a tela brilhante dos celulares. A questão é, em parte, que esses dispositivos são muito eficazes em proporcionar a adequação do comportamento dos usuários que, amontoados em ambientes on-line, estão sujeitos a estímulos que trazem à tona emoções básicas e são, por conseguinte, facilmente sugestionados.

Exemplos interessantes dessa manipulação a que estamos sujeitos nas redes sociais e de como as tecnologias podem produzir novos desejos e comportamentos são os diversos acontecimentos no cenário político nacional e internacional - tais como, os linchamentos ocorridos na Índia em decorrência de fake news, as recentes eleições presidenciais nos Estados Unidos, na Itália e no Brasil articuladas em redes sociais e grupos de Whatsapp, a eclosão de revoltas populares na Primavera Árabe, assim como as multifacetadas e ainda muito debatidas mobilizações de junho de 2013 no Brasil.

Nessa perspectiva, para Lanier (2018), o problema em última análise é que todos esses fenômenos atuais são dirigidos por um modelo de negócio em que o incentivo é encontrar clientes dispostos a pagar pela modificação do comportamento de outra pessoa. Se nos primórdios da publicidade era possível medir se um produto teve maior aceitação depois de um anúncio ser executado, agora as empresas estão medindo se os indivíduos mudaram seus comportamentos de acordo com o esperado. Ou seja, na medida em que os feeds de notícias e as propagandas nas redes sociais são manipulados e constantemente ajustados para obter um determinado comportamento individual, entende-se que a mudança de comportamento foi, ela mesma, transformada em um produto. E o indivíduo aí produzido vira uma mera mercadoria.

Essa manipulação que se capilariza dia a dia nas redes sociais produz uma conversão dos valores individuais contribuindo para uma individualidade peculiar, com comportamentos e desejos igualmente peculiares subsumidos ao consumo e ao mercado. É importante considerarmos que toda a gama de estereótipos corporais construídos no discurso midiático e a apologia ao consumo têm em comum uma 'moral' da aparência, seja ela acoplada ou não a um ideal de saúde. Esses valores estão de acordo com os princípios de uma sociedade neoliberal, em que os indivíduos são constantemente estimulados à competição coletiva e individual (DARDOT; LAVAL, 2016). O controle, nesse contexto, se exerce de forma cada vez mais individualizada, modelando e modulando subjetividades.

O termo 'controle' foi amplamente trabalhado por Michel Foucault em diversos momentos de sua obra, sendo em um primeiro momento relacionando aos mecanismos de vigilância, aos quais era atribuída a função de prevenir o desvio. Posteriormente, o termo permeou a crítica foucaultiana ao controle social

iii O EdgeRank é o mecanismo que permite filtrar as publicações que surgem no seu mural de acordo com três critérios: afinidade, relevância e tempo. Quanto mais interação entre os perfis ou páginas do Facebook, maior é a afinidade. 
exercido pela sociedade capitalista em formação, que tem urgência de controlar a mão de obra criando para tanto instituições e poderes laterais.

Toda a penalidade do século XIX transforma-se em controle, não apenas sobre aquilo que fazem os indivíduos - está ou não em conformidade com a lei? - mas sobre aquilo que eles podem fazer, que eles são capazes de fazer, daquilo que eles estão sujeitos a fazer, daquilo que eles estão na iminência de fazer (FOUCAULT, 2002, p. 93).

Muitos discursos circulantes são capazes de exercer a função de controle, limitação e validação das regras de poder dentro de uma dada sociedade (FOUCAULT, 2010). Foucault entende o poder como um jogo de relações que por meio de seus mecanismos atua como uma força coagindo, disciplinando e controlando os indivíduos. Ele circula nas relações sociais, é descentralizado, múltiplo e capaz de influenciar comportamentos. Neste sentido, o poder percorre outras esferas de manutenção da vida e das populações organizadas como corpo político (FOUCAULT, 2014). Esse poder disciplinar operante entre os séculos XVIII e XIX constituiu mecanismos disciplinares, como escolas, prisões, quartéis, asilos, com o intuito de disciplinar os corpos e torná-los dóceis e úteis. Essas instituições disciplinares tornam os indivíduos cada vez mais individualizados, classificados e controlados, capazes de desempenhar funções com máximo de rapidez e eficácia ao que se exige. As instituições disciplinares têm como objetivo, segundo Foucault (2020, p. 14), "introjetar o comportamento" dos indivíduos para que obedeçam ao poder sem a vigilância da autoridade (SOUZA; AVELINO; SILVEIRA, 2018).

Outra leitura feita por Foucault (2002) do poder diz respeito ao que ele nomeou biopoder. Ele se dirige à espécie humana esquadrinhando os comportamentos e subtraindo a força de trabalho por meio de uma biopolítica disseminada em diversas instituições. De modo complementar aos dispositivos disciplinares que visavam normalizar os comportamentos e condutas individuais, o biopoder se dedica a analisar dados populacionais, construindo estatísticas e parâmetros para o controle dos processos sociais. O corpo, nesse sentido, é imediatamente biopolítico.

Além dessas duas formas de poder, Foucault (2014) também descreve os dispositivos de segurança que, associados às novas biotecnologias, analisam os riscos a que uma população está submetida a fim de construir novas formas de gestão, prevenção e controle. Se na contemporaneidade o corpo ganhou evidência não sendo mais somente um corpo real de carne, osso, ideias e palavras, mas se fazendo presente no mundo virtual por sua extensão nos perfis de redes sociais, podemos considerar que ele se tornou o lócus privilegiado para o exercício do poder que se dá de forma cada vez mais sutil.

Rosa e Chevitarese (2017) observaram em seu estudo que, por meio das mídias sociais como o Facebook e Snapchat, estamos sendo vigiados e punidos constantemente por nossos pares e 'amigos' nas redes sociais, e que as métricas de engajamento das plataformas (curtidas, compartilhamentos, comentários) são julgadas socialmente. Os autores concluíram que cada plataforma dispõe de uma dinâmica de vigilância e relações de poder diferentes a partir das suas interfaces. O Facebook foi considerado como uma fonte inesgotável de dados registrados pelos próprios usuários, onde tudo que é postado encontra-se passível de julgamento e vigilância social. Por outro lado, as publicações instantâneas pelo Snapchat minimizam a vigilância e enfraquecem as relações de poder na rede, oferecendo uma 'liberdade de expressão' e que, de acordo com Rosa e Chevitarese (2017), pode ser entendido como uma área de relativa 'sombra' para o Panóptico ${ }^{\text {iv }}$ cibernético. Atualmente o Instagram oferece diversas ferramentas de interação, e algumas permitem reproduzir as mesmas dinâmicas de vigilância e controle apresentadas pelos autores, porém em uma só plataforma.

iv Panóptico é um termo utilizado para designar uma penitenciária ideal, concebida pelo filósofo e jurista inglês Jeremy Bentham em 1785, que permite a um único vigilante observar todos os prisioneiros, sem que estes possam saber se estão ou não sendo observados. O medo e o receio de não saberem se estão a ser observados leva-os a adotar a comportamento desejado pelo vigilante. Foucault (2002) utilizaria o termo "panóptico" para tratar da sociedade disciplinar. 


\section{OS IDEAIS DO BOPO E A REALIDADE DO MUNDO VIRTUAL}

Nas redes sociais, assim como na vida cotidiana, os mandatos e as proibições de outrora dão lugar à responsabilidade e à iniciativa que configuram atualmente um novo mandato da sociedade pós-moderna do trabalho (EHRENBERG, 1998), trabalho este que vem cada vez mais avançando e tomando outros domínios da vida. Byung-Chul Han (2017), acompanhando o pensamento de Ehrenberg (1998), aponta que vivemos em uma sociedade do desempenho, na qual o paradigma da disciplina apontado e desenvolvido por Foucault (2014) é substituído pelo esquema positivo do poder.

O sujeito de desempenho é mais rápido e mais produtivo do que o sujeito da obediência disciplinar. Porém, o poder não cancela o dever, e o sujeito do desempenho continua sendo disciplinado e cumpridor das ordens que lhe são impostas de cima. Byung-Chul Han (2017) indica que a sociedade do desempenho traz uma ideia de liberdade e desregulamentação frente ao modo como operava a sociedade disciplinar. Nela a autoexploração é mais produtiva e eficiente do que uma coação desconhecida, provocando um sentimento de liberdade que Han chama de "liberdade coercitiva" (2017, p. 30). O autor chama atenção para o fato de que essa liberdade é paradoxal em virtude das estruturas coercitivas que se transformam em violência e adoecimentos psíquicos.

Para Dardot e Laval (2016) essas mudanças na forma de exercício de poder são correlatas da consolidação do neoliberalismo - entendido como o conjunto de discursos, práticas e dispositivos, sociais, econômicos e subjetivos que determinam o novo modo de governo dos homens segundo o princípio universal da concorrência - que tem com estratégia de ação não só a fragilização da ação coletiva por meio da ampliação da lógica do capital a todas as esferas da vida, mas também por meio de uma profunda mudança nas subjetividades que operam no sentido do egoísmo social e da negação da solidariedade. Com técnicas de poder inéditas, essa 'governamentalidade' neoliberal "escora-se num quadro normativo global que, em nome da liberdade e apoiando-se nas margens de manobra concedidas aos indivíduos, orienta de maneira nova as condutas, as escolhas e as práticas" (p. 21).

Dardot e Laval (2016) consideram com Foucault que o Panóptico de Bentham é emblemático para pensar essa modelagem subjetiva própria ao neoliberalismo, cuja gestão das mentes visa penetrar e educar o pensamento a fim de conduzir os interesses. A postulação e construção da liberdade de escolha tão cara a esse sistema "pressupõe que os sujeitos sejam conduzidos por uma 'mão invisível' a fazer as escolhas que serão proveitosas a todos e a cada um" (DARDOT; LAVAL, 2016, p. 325). Nesse sentido, nada mais oportuno do que interrogar como isso opera nas redes sociais.

No que diz respeito às mídias digitais, Han (2017) nos alerta que somos desprogramados por meio dessa nova mídia sem que possamos compreender a mudança de paradigma em curso. Ao nos arrastar atrás dessas mídias que transformam nosso comportamento, nossa percepção, nossas sensações e pensamentos, a cegueira e a estupidez passam a configurar a crise atual. O poder em jogo nas mídias sociais não é simétrico, visto que fundamenta uma relação hierárquica e não dialógica.

No contexto das mídias sociais em que vemos a proliferação de mobilizações sociais (SERRA JÚNIOR; ROCHA, 2013) que a princípio se baseiam na indignação, Han (2017, p. 21) afirma que "as ondas de indignação são eficientes em mobilizar e compactar a atenção. Por causa de sua fluidez e volatilidade elas não são, porém, apropriadas para organizar o discurso público, a esfera pública [...] falta a elas a estabilidade, a constância e continuidade que seriam indispensáveis para o discurso público”.

Nesse sentido, indica que, com a revolução digital, tornamo-nos um "enxame digital" (HAN, 2017, p. 26), que se distingue das massas tradicionais - tal qual as descritas por Le Bon (1954) em Psicologia das multidões -, uma vez que é formada por indivíduos singularizados que não compartilham uma alma. 
A massa tem características que não se referem aos indivíduos, mas formam um perfil próprio. Segundo Han, é esse espírito da massa que falta ao enxame digital.

Diferentemente das mídias de massa tradicionais como o rádio que tem um sentido de transmissão unilateral, as mídias digitais desmediatizam a comunicação, na medida em que todos produzem e enviam informação. Ao final, a escrita singular fica perdida diante de uma exigência de transparência da escrita coletiva que anuncia uma mudança normativa: ela dita o que "é" e o que "deve ser", definindo o novo "ser" (LE BON, 1954, p. 38).

A mídia digital furta da comunicação a tatilidade e a corporeidade, o que leva as pessoas a evitarem cada vez mais o contato real com outros, e a comunicação se torna cada vez mais sem corpo e sem rosto. Além disso, o imperativo da sociedade da transparência (HAN, 2017) é que tudo deve ser dito, toda informação deve ser acessível, o que desaloja a verdade de seu velamento. Contudo, para Han (2018, p. 76), poder e informação não combinam, pois "o poder gosta de se ocultar no segredo".

Por não ser em si mesmo uma mídia dialógica, a comunicação nas mídias digitais se caracteriza como uma máquina narcisista, que destrói o espaço público, aguçando a individualização do ser humano. Nesse sentido,

o projeto para o qual o sujeito se liberta se mostra ele mesmo como figura de coação. Ele desdobra a coação na forma do desempenho, da auto-otimização e da auto-exploração [...] a liberdade é, na verdade, a figura oposta a coação. Agora, essa figura oposta, produz, ela mesma, coações. Mais liberdade significa mais coações (HAN, 2018, p. 87).

\section{A FÁBRICA DIGITAL DA SUBJETIVIDADE BOPO}

Em analogia à perspectiva da sociedade do desempenho, os influenciadores digitais apresentam o perfil de herói empreendedor (BENTES, 2018), além de aparentar uma vida bem-sucedida, demonstram ser produtivos e empresários de si mesmos. Da mesma forma, o estilo de vida 'perfeito' ou 'politicamente correto' exibido nos perfis do Instagram pelos influenciadores digitais Body Fitness e pelas ativistas do BoPo transmite uma ideia naturalizada de que o espectador também é capaz de conquistar e superar seus limites, funcionando como 'guias de sua própria modelização'. Segundo Bentes (2018), tornar-se empreendedor da sua própria vida nas redes sociais é exibir e manifestar seus empreendimentos ao olhar do outro com o objetivo de influenciar seus espectadores.

Para Han (2018), a sociedade da transparência se aproxima estruturalmente da sociedade da vigilância, pois afirma que onde se tem acesso rápido e fácil à informação, a sociedade muda da confiança para o controle e a transparência; o que implica dizer que a vigilância e o controle são uma parte inerente da comunicação digital. Nesse sentido, o que vivemos na atualidade não é mais uma sociedade de controle biopolítico apontada por Foucault (2002), mas uma sociedade de transparência psicopolítica, nos termos de Han. No lugar do biopoder, temos o psicopoder que, com a ajuda da vigilância digital, pode ler e controlar pensamentos, pois tem condições de intervir nos processos psicológicos.

Diante de um novo formato de comunicação que se desdobrou no contexto da sociedade neoliberal, é perceptível o impacto das redes sociais sobre o comportamento humano, por meio dos novos hábitos sociais, modismos e até mesmo se tornando possíveis causas de algumas síndromes e transtornos. A influência do Instagram, seja pelo próprio conteúdo produzido pelo influenciador digital ou pelos serviços que chegam por meio do machine learning ${ }^{v}$, condiciona a necessidade de consumo e de uma identidade virtual que causa repercussão direta na produção de subjetividades individualizadas e consumistas. Os movimentos

v Sistema operacional no qual os algoritmos são habilitados a 'aprender' um conjunto de dados capazes de criar um padrão de informação e, assim, mostram conteúdos que previsivelmente são considerados relevantes ao usuário. 
aqui observados retratam com naturalidade a fusão de perfis que buscam expor seus ideais com aqueles que roteiam e ganham seguidores e likes.

Ainda que o movimento BoPo preze por uma liberdade de expressão e exibição de corpos fora da norma estética atual, podemos interrogar até que ponto eles também operam em uma lógica de controle e produção de subjetividades que se afirmam por essa liberdade constrangida e limitada, muitas vezes, ao âmbito digital.

Cwynar-Horta (2016) questiona em seu estudo o domínio da indústria sobre os movimentos que estavam marginalizados, pois quando são expostos à ordem social se tornam alvos para obter ganhos financeiros. Ao restabelecer seu poder sobre as massas, o mercado dá as regras de como se libertar da opressão da norma estética ou da saúde estetizada, criando uma outra norma. Dessa forma, o grupo que busca ter os seus 'corpos válidos' da maneira que são acabam encontrando-se novamente dependentes de um mercado de commodities mascarado por um ativismo que positiva o corpo ao mesmo tempo que o recaptura em uma liberdade coercitiva.

Ainda que pareça um exagero crítico, vale considerar que as postagens relacionadas ao BoPo produzem certo tipo de manipulação que atende aos mesmos mecanismos de poder utilizados pelo neoliberalismo e contribui para a construção de um certo tipo de individualidade que se mostra contraditória em relação aos movimentos coletivos baseados no princípio do comum. Como nos indicou Foucault (2010), muitos discursos circulantes são capazes de exercer a função de controle, limitação e validação das regras de poder dentro de uma dada sociedade, o que aguça nosso olhar para as novas formas de controle que se mostram travestidas em discursos libertários e motivacionais. Segundo Dardot e Laval (2016), as injunções sociais para sermos nós mesmos e nos amarmos como somos que se fazem ouvir nos perfis relacionados ao movimento BoPo estão inseridas em um discurso que faz do desejo legítimo uma ordem a ser cumprida. Para os autores, o "management é um discurso ferrenho que usa palavras de veludo" (p. 345), dentre as quais 'autoestima' é a palavra mágica.

A permanente incitação à retomada do domínio sobre o próprio corpo e sobre a própria vida reflete uma tendência das sociedades neoliberais que fomentam o empreendedorismo de si como saída possível para alienação própria à sociedade capitalista. Por princípio, o empreendedorismo de si supõe a integração entre a vida pessoal e profissional que implica um avanço dos dispositivos de controle sobre a vida íntima. O paradoxo da liberdade é que ela cobra um preço alto que só pode ser pago com a própria subjetividade.

O movimento aqui observado retrata com naturalidade a fusão de pessoas e perfis que buscam expor seus ideais, ganhando seguidores e likes. A partir da discussão aqui proposta, compreendemos que a estetização da saúde somada à cultura medicalizada reforça a associação do corpo magro à saúde, que por consequência gera um preconceito e uma fobia em torno da gordura corporal. Estes fatores são oportunos na sociedade capitalista de consumo, pois o corpo que não atende a um determinado padrão estético vive em uma busca incessante de adequação e validação social. A violência da estratégia neoliberal é de tal ordem que a saúde se transformou ela própria em uma mercadoria que alimenta um voraz mercado consumidor de medicamentos e suplementos em busca de uma supernormalidade (NEVES et al., 2015). Assim, o discurso da vida saudável e da boa alimentação acaba por legitimar e estimular cuidados com o corpo, ao mesmo tempo que fomenta a vaidade e o embelezamento como atores fundamentais na lógica consumista.

O enxame de pessoas em busca de viver belo, feliz e livre é presa certa do capitalismo afoito a criar novas necessidades, demandas e produtos prontos para satisfazer indivíduos cada vez mais narcisistas. Em última análise, observa-se que tanto os perfis Body Fitness quanto os perfis Body Positive atendem a essa lógica que visa incutir nos indivíduos mecanismos de regulação e controle e cria, por assim dizer, uma nova normatividade cuja face sombria incita uma densa vigilância, uma rastreabilidade cada vez mais precisa dos indivíduos na internet, sua avaliação cada vez mais mesquinha e a proliferação de formas cada vez 
mais insidiosas de autocontrole dos próprios sujeitos (DARDOT; LAVAL, 2016). Se nos perfis Body Fitness essa normatividade é mais explícita, pois as mensagens são mais diretas, nos perfis Body Positive isso não é obvio e exige de nós um olhar crítico aguçado. Da mesma maneira, ao interrogarmos os mecanismos de controle do corpo feminino presentes nos perfis BoPo, podemos sustentar a crítica à estetização da saúde que pode também se camuflar diante da lógica ao mesmo tempo massificadora e individualizante das redes sociais. Ainda que no movimento BoPo haja uma resposta ou uma resistência aos ditames da sociedade sobre os 'corpos válidos', pode-se observar que os perfis BoPo atendem a um mercado em crescimento e à mesma lógica medicalizante de regulação do corpo, mediado por um discurso neoliberal travestido de aceitação de si mesmo, de amor próprio e de recusa da norma gordofóbica.

\section{REFERÊNCIAS}

ALMEIDA, Marcos Inácio Severo de; COSTA, Milena; COELHO, Ricardo Limongi França; SCALCO, Paulo Roberto. Engaja-me e atraia-me, então eu compartilharei: uma análise do impacto da categoria da postagem no marketing viral em uma rede social. Revista Brasileira de Gestão de Negócios, São Paulo, v. 18, n. 62, p. 545-569, 2016. DOI: http://dx.doi.org/10.7819/rbgn.v18i62.2620. Disponível em: https://rbgn.fecap.br/RBGN/ article/view/2620/pdf. Acesso em: 15 mar. 2020.

ARANDAS, Luciana P. R. Por dentro da hashtag Body Positive: ciberativismo e a emergência de uma nova visão do corpo nas redes sociais da internet. In: ENCONTRO ANUAL DA ANPOCS, 42., 22-26 out. 2018 , Caxambu. Anais [...] Caxambu: Associação Nacional de Pós-Graduação e Pesquisa em Ciências Sociais - ANPOCS, 2018, p. 1-24. Disponível em: https://www.anpocs.com/index.php/encontros/papers/42-encontroanual-da-anpocs/spg-5/spg24-3/11587-por-dentro-da-hashtag-body-positive-ciberativismo-e-a-emergencia-deuma-nova-visao-do-corpo-nas-redes-sociais-da-internet/file. Acesso em: 15 mar. 2020.

BAIR, Carie E.; KELLY, Nichole R.; SERDAR, Kasey L.; MAZZEO; Suzanne E. Does the internet function like magazines? An exploration of image-focused media, eating pathology, and body dissatisfaction. Eating Behaviors, New York, v. 13, n. 4, p. 398-401, 2012. DOI: https://doi.org/10.1016/j.eatbeh.2012.06.003. Disponível em: https://www.sciencedirect.com/science/article/abs/pii/S147101531200075X. Acesso em: 15 mar. 2020.

BAUMAN, Zygmunt. As redes sociais são uma armadilha. Entrevista cedida a Ricardo de Querol. EI País, Madrid, 8 jan. 2016. Disponível em: https://brasil.elpais.com/brasil/2015/12/30/cultura/1451504427 675885. html. Acesso em: 14 maio 2018.

BENTES, Anna Carolina Franco. Quase um tique: economia da atenção, vigilância e espetáculo a partir do Instagram. 2018. Dissertação (Mestrado em Comunicação e Cultura) - Universidade Federal do Rio de Janeiro, Rio de Janeiro, 2018.

BODY IMAGE MOVEMENT. Glenside: The Movement, 2019. Disponível em: https://bodyimagemovement. com/. Acesso em: 23 maio 2019.

CASTRO, Gisela G. S. Entretenimento, sociabilidade e consumo nas redes sociais: cativando o consumidorfã. Revista Fronteiras, São Leopoldo, v. 14, n. 2, p. 133-140, 2012. DOI: https://doi.org/10.4013/ fem.2012.142.07. Disponível em: http://revistas.unisinos.br/index.php/fronteiras/article/view/fem.2012.142.07. Acesso em: 15 mar. 2020.

CONRAD, Peter. The Medicalization of Society: On the Transformation of Human Conditions into Treatable Disorders. Baltimore: The Johns Hopkins University Press, 2007.

COUTINHO, Carolina; PRADO, Shirley Donizete; SEIXAS, Cristiane Marques. O tratamento da obesidade e o risco dos transtornos alimentares. In: RODRIGUES, Phillipe; CARDOSO, Erika; PALMA, Alexandre (org.). Obesidade e sociedade. Curitiba: CRV, 2019. p. 75-92.

CRABBE, Megan Jayne. Body Positive Power: how to stop dieting, make peace with your body and live. London: Vermilion, 2017.

CWYNAR-HORTA, Jessica. The commodification of the Body Positive Movement on Instagram. Stream: Interdisciplinary Journal of Communication, Burnaby, v. 8, n. 2, p. 36-56, 2016. Disponível em: https:// journals.sfu.ca/stream/index.php/stream/article/view/203/180. Acesso em: 15 mar. 2020. 
DARDOT, Pierre; LAVAL, Christian. A nova razão do mundo: ensaio sobre a sociedade neoliberal. São Paulo: Boitempo, 2016.

EHRENBERG, Alain. La fatigue d'être soi. Paris: Odile Jacob, 1998.

EMBRACE. Direção e roteiro de Taryn Brumfitt. Produção de Anna Vincent e Taryn Brumfitt. Produção executiva de Timothy White e Mathew Brumfitt. Edição de Lindi Harrison e Bryan Mason. Sydney: ETC Films Pty Ltd. 2016. 1 vídeo (86 min), son., color.. Disponível em: https://vimeo.com/ondemand/embrace. Acesso em: 23 jul. 2020.

FELL, James S. The 'before and after' photo that changed everything for this woman. Los Angeles Times, Los Angeles, 22 abr. 2017. Disponível em: https://www.latimes.com/health/la-he-taryn-brumfitt-20170422-story.html. Acesso em: 10 jun. 2020.

FERREIRA, Francisco Romão. A estetização da saúde. In: BAGRICHEVSKY, Marcos; ESTEVÃO, Adriana. Saúde coletiva: dialogando sobre interfaces temáticas. Ilhéus: EDITUS, 2015. p. 121-140.

FOUCAULT, Michel. A ordem do discurso: aula inaugural no Collège de France, pronunciada em 2 de dezembro de 1970. 24. ed. São Paulo: Loyola, 2010.

FOUCAULT, Michel. A verdade e as formas jurídicas. Rio de Janeiro: NAU Editora, 2002.

FOUCAULT, Michel. Vigiar e punir: o nascimento da prisão. 42. ed. Petrópolis: Vozes, 2014.

FRANCISCO, Lucas Vieira; DIEZ-GARCIA, Rosa Wanda. Abordagem terapêutica da obesidade: entre conceitos e preconceitos. Demetra: Alimentação, Nutrição \& Saúde, Rio de Janeiro, v. 10, n. 3, p. 705-716, 2015. DOI: https://doi.org/10.12957/demetra.2015.16095. Disponível em: https://www.e-publicacoes.ueri.br/ index.php/demetra/article/view/16095. Acesso em: 15 mar. 2020.

FURTADO, Everley Rosane Goetz. Representações sociais do corpo, mídia e atitudes. 2009. Tese (Doutorado em Psicologia) - Universidade Federal de Santa Catarina, Florianópolis, 2009.

GOFFMAN, Erving. Estigma: notas sobre a manipulação da identidade deteriorada. 4. ed. Rio de Janeiro: Guanabara Koogan, 1988.

HAN, Byung-Chul. No exame: perspectivas do digital. Petrópolis: Vozes, 2018.

HAN, Byung-Chul. Sociedade do cansaço. 2. ed. Petrópolis: Vozes, 2017.

KEMP, Simon. Digital in 2018: world's internet user pass the 4 billion mark. We Are Social, Nova lorque: We are Social Inc, 2018. Disponível em: https://wearesocial.com/blog/2018/01/global-digital-report-2018. Acesso em: 23 jul. 2020.

KOZINETS, Robert V. On netnography: initial reflections on consumer research investigations of cyberculture. Advances in Consumer Research, [s. I.], v. 25, p. 366-371, abr. 1998. Disponível em: https://www.acrwebsite. org/volumes/8180/volumes/v25/NA-25. Acesso em: 15 mar. 2020.

LANIER, Jaron. Ten arguments for deleting your social media accounts right now. New York: Henry Holt and Company, 2018.

LE BON, Gustave. Psicologia das multidões. Rio de Janeiro: F. Briguet \& Cia, 1954.

MATTOS, Rafael; LUZ, Madel Therezinha. Sobrevivendo ao estigma da gordura: um estudo socioantropológico sobre obesidade. Physis, Rio de Janeiro, v. 19, n. 2, p. 489-507, 2009. https://doi.org/10.1590/S010373312009000200014. Disponível em: https://www.scielo.br/scielo.php?script=sci arttext\&pid=S010373312009000200014\&lng=pt\&tlng=pt. Acesso em: 19 mar. 2020.

NEVES, Alden dos Santos et al. A nutrição na busca da supernormalidade: da medicalização da comida à farmacologização social da nutrição. In: PRADO, Shirley Donizete; KRAEMER, Fabiana Bom; SEIXAS, Cristiane Marques; FREITAS, Ricardo Ferreira. Alimentação e consumo de tecnologias. Curitiba: CRV, 2015. p. 17-32.

ORTEGA, Francisco. 0 corpo incerto: corporeidade, tecnologias médicas e cultura contemporânea. Rio de Janeiro: Garamond, 2008. 
PEIXOTO, Zeca. O Facebook para além da rede social: o usuário como consumidor-mercadoria. In: PORTO, Cristiane; SANTOS, Edméa (org.). Facebook e educação: publicar, curtir, compartilhar. Campina Grande: EDUEPB, 2014. p. 221-236. Disponível em: http://books.scielo.org/id/c3h5q/13. Acesso em: 14 mar. 2020.

ROSA, Fábio Medeiros da; CHEVITARESE, Leandro. Vigilância e relações de poder nas redes sociais: questões éticas na sociedade contemporânea. Organicom, São Paulo, v. 14, n. 27, p. 59-69, 2017. DOI: https://doi.org/10.11606/issn.2238-2593.organicom.2017.144108. Disponível em: http://www.revistas.usp.br/ organicom/article/view/144108. Acesso em: 15 mar. 2020.

SEIXAS, Cristiane Marques; BIRMAN, Joel. O peso do patológico: biopolítica e vida nua. História, Ciências, Saúde-Manguinhos, Rio de Janeiro, v. 19, n. 1, p. 13-26, 2012. DOI: https://doi.org/10.1590/ S0104-59702012000100002. Disponível em: https://www.scielo.br/scielo.php?script=sci arttext\&pid=S010459702012000100002\&lng=pt\&tlng=pt. Acesso em: 15 mar. 2020.

SEIXAS, Cristiane Marques; LUCENA, Bianca Bulcão. O mundo não é um spa: sobre a ética do desejo na clínica da obesidade. In: PRADO, Shirley Donizete et al. (org.). Estudos socioculturais em alimentação e saúde: saberes em rede. Rio de Janeiro: EDUERJ, 2016. p. 279-296.

SERRA JÚNIOR, Gentil Cutrim; ROCHA, Lourdes de Maria Leitão Nunes. A Internet e os novos processos de articulação dos movimentos sociais. Revista Katálysis, Florianópolis, v. 16, n. 2, p. 205-213, 2013. DOI: https://doi.org/10.1590/S1414-49802013000200006. Disponível em: https://www.scielo.br/scielo. php?script=sci arttext\&pid=S1414-49802013000200006\&lng=pt\&tlng=pt. Acesso em: 15 mar. 2020.

SODRÉ, Muniz. Antropológica do espelho: uma teoria da comunicação linear e em rede. 2. ed. Petrópolis: Vozes, 2002.

SOUZA, Joyce; AVELINO, Rodolfo; SILVEIRA, Sérgio Amadeu da. A sociedade de controle: manipulação e modulação nas redes digitais. São Paulo: Hedra, 2018.

THE BODY POSITIVE INSTITUTE. Berkeley: The Body Positive, 2019. Disponível em: https://thebodypositive. orgl. Acesso em: 23 maio 2019.

TIGGEMANN, Marika; ZACCARDO, Mia. Strong is the new skinny: a content analysis of \#fitspiration images on Instagram. Journal of Health Psychology, [s. I.], v. 23, n. 8, p. 1003-1011, 2016. DOI: https://doi.org/10.1177/1359105316639436. Disponível em: https://journals.sagepub.com/ doi/10.1177/1359105316639436. Acesso em: 15 mar. 2020.

VILHENA, Junia de; MEDEIROS, Sergio; NOVAES, Joana de Vilhena. A violência da imagem: estética, feminino e contemporaneidade. Revista Mal Estar e Subjetividade, Fortaleza, v. 5, n. 1, p. 109-144, 2005. Disponível em: http://pepsic.bvsalud.org/scielo.php?script=sci arttext\&pid=S1518-61482005000100006\&lng=e n\&nrm=iso\&tlng=pt. Acesso em: 15 mar. 2020.

WITT, Juliana da Silveira Gonçalves; Zanini, SCHNEIDER; Aline Petter. Nutrição estética: valorização do corpo e da beleza através do cuidado nutricional. Ciência \& Saúde Coletiva, Rio de Janeiro, v. 16, n. 9, p. 39093916, 2011. DOI: https://doi.org/10.1590/S1413-81232011001000027. Disponível em http://www.scielo.br/ scielo.php?script=sci arttext\&pid=S1413-81232011001000027\&lng=pt\&nrm=iso. Acesso em: 15 mar. 2020. 